\title{
Girls preferences for different garment features in designing western dresses
}

VARSHA DEVI AND HARMINDER KAUR SAINI

Received: 12.02.2015; Revised: 27.03.2015; Accepted: 12.04.2015

See end of the paper for authors' affiliations

\section{VARSHA DEVI}

Department of Apparel and

Textile Science, College of Home

Science, Punjab Agricultural

University, LUDHIANA (PUNJAB)

INDIA

Email : varshubarwal@gmail.com
-ABSTRACT : For this study, a total of 90 college going girls were selected through purposive random sampling technique. Preferences of college girls for silhouettes, fabric types, colour combinations and other constructional features were taken. The data collected revealed that Aline, balloon, sheath, mermaid and ball gown silhouettes were the five most preferred ones. Plain georgette and cotton fabrics, black and red colours in single and two coloured combination for western dresses with round shape neckline were most preferred. Among constructional features, respondents preferred gathers with elastic, knife pleats, pin tucks, round shaped yoke and gathered ruffles. Embroidery as surface embellishment techniques and lace, swarovski and sequins for surface embellishment were most preferred by the respondents.

KEY WORDS: Western dresses, Silhouettes, Embellishment, Design, Most preferred

- HOW TO CITE THIS PAPER : Devi, Varsha and Saini, Harminder Kaur (2015). Girls preferences for different garment features in designing western dresses. Asian J. Home Sci., 10 (1) : 79-83. 